\title{
Spatiotemporal Effects of Land Use and River Morphological Change on the Microclimate of Rajshahi Metropolitan Area
}

\author{
Mst Ilme Faridatul \\ Department of Urban and Regional Planning, Rajshahi University of Engineering \& Technology, Rajshahi, Bangladesh \\ Email:mifaridatul@ruet.ac.bd, ilme0309@gmail.com
}

How to cite this paper: Faridatul, M.I. (2017) Spatiotemporal Effects of Land Use and River Morphological Change on the Microclimate of Rajshahi Metropolitan Area. Journal of Geographic Information System, 9, 466-481. https://doi.org/10.4236/jgis.2017.94029

Received: May 31, 2017

Accepted: August 8, 2017

Published: August 11, 2017

Copyright $\odot 2017$ by author and Scientific Research Publishing Inc. This work is licensed under the Creative Commons Attribution International License (CC BY 4.0).

http://creativecommons.org/licenses/by/4.0/

(c) (i) Open Access

\begin{abstract}
Microclimate is a climatic phenomenon of a very local area that is affected by the variation of natural earth surfaces in urban area. The urban growth expedites to change land use and land cover pattern of a city that modify the built environment, alter the composition of the atmosphere and form a distinct local climate in the cities. The radical land use and land cover change also alters the meteorological condition of a city. The relationship between land use land cover and thermal environment has long been studied to identify the impacts of urban growth but for this study area no such effort is taken. This study focuses on detecting the changing pattern of the cities adjacent Padma River and land uses, finally the impacts of such changes on the microclimate are assessed. This study is conducted based on Landsat time series data of 1989, 1996, 2005 and 2015 using ENVI and ArcGIS 10.2 softwares. The result demonstrates that the city is experiencing continuous change in land cover pattern, where the city centre is more vulnerable to change than its fringe. Another significant change is observed in the morphology of river Padma; it shows continuous shift of the river channel and increase in the Char land. The interactions of land use land cover and LST depicts a continuous increase in the mean surface temperature over bare soil following impervious area. The results underscore that two factors are contributing to influence the microclimate of the study area: First, the areal extent of surface water particularly the river Padma is losing stream and generating more bare soil (Char Land); second, impervious area is increasing and natural earth surfaces are decreasing.
\end{abstract}

\section{Keywords}

Land Use, Microclimate, Remote Sensing, Surface Temperature

\section{Introduction}

Urbanization expedites to change natural earth surfaces that results to decline 
vegetation and water bodies, in contrary increases impervious surfaces. The existence of water bodies provide cooling effect through the process of evapotranspiration. The incidence of solar radiation on the surface water results to vaporize water and reduce the heat thereby, it helps to cool the surrounding environment. Rapid urbanization influences to fill water bodies therefore, increases in mean air temperatures is becoming an increasingly significant phenomenon in the world [1]. Particularly, urbanization induced land use and land cover change alters the meteorological condition of a city. The consequences of urbanization result in the reduction of rainfall, increment in the air temperature, relative humidity and energy demand that in turn aggravate the problems of urban heat island [2]. Land use and land cover composition shapes the built environment and leads to change the microclimate of a city.

The disruption of the natural and built environments caused by urban growth is serious in the climatic point of view that in turn results excessive heat storage and high concentration of air pollution [3]. Urbanization usually gives rise to a dramatic change in the land use land cover pattern of the city that results in the reduction of greenery and water bodies and an increase in the impervious areas [2]. Microclimate is defined as the climatic environment of a very local area that is affected by the alteration of vegetation and impervious surfaces in city area [4]. The land use and land cover along with the Land Surface Temperature (LST) is a climatic phenomenon that reflects an integration of heterogeneous matrix of the urban microclimates [5]. Land surface temperature is a key factor that results the interaction between land surface and atmosphere, exchange of matter and energy [6]. Surface temperature is an important factor in urban microclimate that provides quantitative information on the effects of the land use and land cover change [7]. The LST derived from satellite images is a key variable to understand the impacts of land use land cover changes [8]. The urban heat island effect resulting from land use land cover change is attracting attention among the global scientists, environmentalist, geographers and city planners [2]. Several studies on the land use and land cover change; urban growth and surface warming have been conducted over 50 years. For example, Huang, et al. [2] conducted a research to assess the effects of different types of urban land cover on air temperature. Trees and vegetation play vital role to mitigate UHI effects thus [9] conducted a study to identify the green spaces growth impact on the urban microclimate. The pattern of rapid urbanization and its impact on surface warming over eastern China was detected by [10] using nighttime light images. On the other hand, [8] used Landsat imagery to explore urbanization induced land use land cover changes and its impact on the land surface temperature. Using standard statistical technique a study was conducted to assess the impact of urbanization driven land use change on the microclimate as extreme precipitation events in and around cities [11]. Urban Heat island intensity is relevant to the structure of the land use and land cover changes so Landsat thermal imagery were used to detect the patterns of UHI in rapidly urbanizing city, Jinan, China [12]. Another study was conducted on the relationship between the land surface 
temperatures and land cover changes in Dhaka Metropolitan Area [13]. Urban heat island (UHI) is considered as one of the main causes of urban micro-climate warming thus [14] applied a simple regression model for the derivation of future LST for the capital city Dhaka, Bangladesh. Hasan et al. (2014) used NOAA satellite images to estimate the land surface temperature of Bangladesh [15]. On the other hand, [5] conducted a study was in the Phoenix metropolitan area to examine spatial patterns of land use, plant density, and microclimate. The urban microclimate affects the levels of human comfort also affects the biotic process of the plants and animals [5].

Rajshahi has a tropical dry climate with limited rainfall and it seems that the city is becoming warm day by day. Worldwide a number of studies have provided the basis for understanding the relationship between land use land cover change and its impact on the land surface temperature. However, none such effort is taken for this study area. Recently, Rajshahi is experiencing urbanization; in addition, the adjacent river the Padma is dewatering and increasing bare soil (Char land). Therefore, this research is conducted selecting Rajshahi Metropoli$\tan$ Area as a typical study area. The goal of the study is to explore the temporal land use and morphology of the River Padma and to investigate the impacts of such changes on the microclimate of the city. The time series data of Landsat is used to prepare land use and land surface temperature maps. Finally, the relationships are assessed in terms of land use and LST by taking two transect profiles. It is expected that the findings of this study will bring about more insights for understanding the climatic variability over the last several decades in the Rajshahi Metropolitan area. In addition, the study may serve as guidance to the policy makers and planners for sustainable management of urban environment.

\section{Data and Study Area}

\subsection{Study Area}

Rajshahi the fourth largest metropolitan city of Bangladesh is selected as the study area for this research. The study area is located to the northwestern part of Bangladesh along the banks of the River Padma. It lies at $24^{\circ} 07^{\prime}$ to $24^{\circ} 43^{\prime}$ north latitudes and $88^{\circ} 17^{\prime}$ to $88^{\circ} 58^{\prime}$ east longitudes (Figure 1). The study area covers an area of $204.85 \mathrm{~km}^{2}$, excluding the char land of the River Padma it is about 170 $\mathrm{km}^{2}$ of which the city core (Rajshahi City Corporation) area is only $46.9 \mathrm{~km}^{2}$. The city has developed from a small population of 40,000 in 1951 to about 339,932 in 2001 and 449,757 in 2011 (BBS, 2011) [16].

Rajshahi is the prominent city in the north Bengal of Bangladesh. The historical growth of Rajshahi Metropolis in terms of urban population shows an increasing trend but the level of urbanization is very slow compared to the other metropolitan cities of Bangladesh. Dominance of agriculture, absence of industrial activities on a significant scale is a characteristic feature of this area. It was simply a district town prior to 1947 that had become a divisional headquarters in 1947 and finally achieved the status of City Corporation in 1991 [17]. The most significant feature of this area is its tropical wet and dry climate. The climate is 

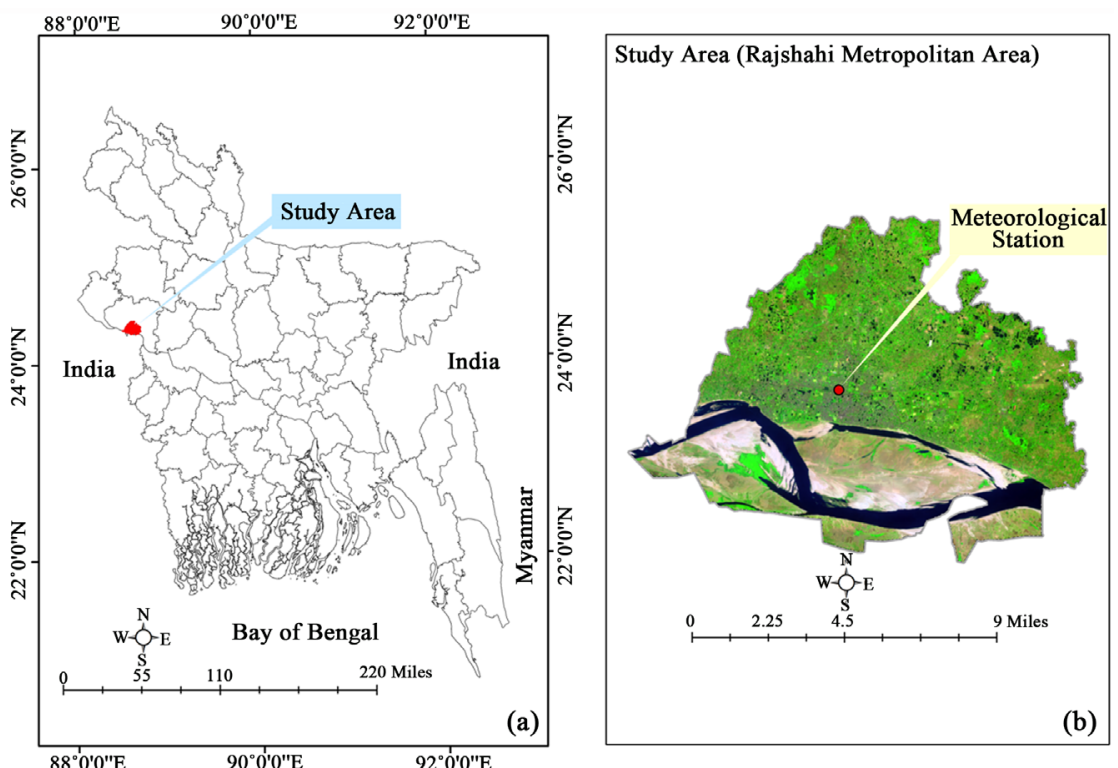

Figure 1. Study area: (a) Location of Rajshahi in Bangladesh; (b) Rajshahi city core and its surroundings.

generally marked with monsoons, high temperature, considerable humidity and moderate rainfall. The hot season commences early in March and continues till the middle of July. The maximum mean temperature is about $32^{\circ} \mathrm{C}$ to $36^{\circ} \mathrm{C}$ during the months of April, May, June and July and the minimum temperature is about $10^{\circ} \mathrm{C}$ in January. The city has a sub-tropical monsoon climate, which falls within a low rainfall zone of the country with average annual rainfall 1100 $1350 \mathrm{~mm}$ [17].

\subsection{Data}

Multi-temporal Landsat satellite imagery and meteorological data are used for this study. The Landsat satellite imagery of 1989, 1996, 2005 and 2015 is collected from the official website of US Geological Survey (Table 1). Landsat Path 138 and Row 43 cover the whole study area. Map Projection of the collected satellite images is Universal Transverse Mercator (UTM) within Zone $45 \mathrm{~N}-\mathrm{Da}$ tum World Geodetic System (WGS) 84 and the pixel size is 30 meters. To obtain better result utmost effort is given to select the satellite imagery of similar dates and months but due to the non-availability of cloud free data there is a little variation in the collected satellite images.

Meteorological data is an important factor of urban microclimate that provides quantitative information on the effects of land use and land cover change [7]. Therefore, the climatic records (precipitation, temperature, relative humidity and wind speed) from 1980 to 2015 are collected from Bangladesh Meteorological Department (BMD). To assess microclimate, the climatic records from one station is not adequate but one of the limitations of this research is that the study area contains only one meteorological station. Thus, the climatic data from only one station is collected. In addition, the administrative boundary of the study area is collected to prepare the base map. 
Table 1. Summary of landsat imagery used in this study.

\begin{tabular}{cccc}
\hline Sensor & Path & Row & Date of Acquisition \\
\hline LANDSAT 5 (Thematic Mapper) & 138 & 043 & March 16, 1989 \\
LANDSAT 5 (Thematic Mapper) & 138 & 043 & April 4, 1996 \\
LANDSAT 5 (Thematic Mapper) & 138 & 043 & April 13, 2005 \\
LANDSAT 8 (Operational Land Imager) & 138 & 043 & March 24, 2015 \\
\hline
\end{tabular}

\section{Methods}

The study covers three parts namely land use and land cover classification, retrieval of land surface temperature and assessing the impact of land use and land cover change on the microclimate.

\subsection{Image Processing and Classification}

To ensure high accuracy, the temporal land use classification requires conversion of Digital Number values to surface reflectance values. Therefore, before classification the atmospheric and radiometric correction is done using ENVI software. In this research, four Lands at imagery acquired between 1989 and 2015 are used (Table 1). The collected imagery are classified based on four land cover classes: built up, water, vegetation and bare soil (Table 2). As the resolution of the images is not good enough therefore, careful consideration is given to select the training samples. In this study, first, unsupervised classification is performed to identify initial spectral clusters in the images. Second, end members are selected analyzing the spectral reflectance values and the spectral indices of NDVI, NDBI, and NDWI. Lastly, the Support Vector Machine (SVM) classification approach is applied to classify the imagery. To increase the accuracy of the classification, the initial classified results are revised based on the physical feature data (Field survey data of RDA, 2002) and Google earth images.

\subsection{Estimation of Land Surface Temperature (LST)}

Land surface temperature is closely related to the land use land cover pattern. It is estimated using the thermal band of Landsat imagery. The band $6(10.40 \mu \mathrm{m}$ 12. $50 \mu \mathrm{m})$ of the Landsat 5 Thematic Mapper and band 10 TIRS $1(10.6 \mu \mathrm{m}-11$. $19 \mu \mathrm{m})$ and band 11 TIRS $2(11.5 \mu \mathrm{m}-12.51 \mu \mathrm{m})$ of the Landsat 8 Operational Land Imager are used to estimate LST. The procedures described in the Landsat 5 science data users handbook of NASA and Landsat 8 data users handbook of USGS are adopted to estimate LST as follows: First, the values of the Digital Number (DN) of the thermal bands are converted to sensor radiance using Equations (1) and (2) for Landsat 5 and Landsat 8 respectively.

$$
L_{\lambda}=\left(\left(L_{\max \lambda}-L_{\min \lambda}\right) /\left(Q C a l_{\max }-Q C a l_{\min }\right)\right) *\left(Q C a l-Q c a l_{\min }\right)+L_{\min \lambda}
$$

where

$$
\begin{aligned}
& L_{\lambda}=\text { Sensor Radiance } \\
& L_{\max \lambda}=\text { Maximum Radinace of Band } 6
\end{aligned}
$$


Table 2. Land cover classes of the study area.

\begin{tabular}{cc}
\hline Land cover & Description \\
\hline Builtup & $\begin{array}{c}\text { Impervious surfaces: residential, commercial, industrial, } \\
\text { roads and any other built structures. }\end{array}$ \\
Water & $\begin{array}{c}\text { Rivers, lakes, ponds and any other wetlands. } \\
\text { Agricultural lands, forest lands, shrub lands, } \\
\text { Vegetation }\end{array}$ \\
trees and any other vegetative surfaces \\
Bare soil & $\begin{array}{c}\text { Landfill sites, sand, exposed soil and land with } \\
\text { sparse vegetation and without any vegetation }\end{array}$ \\
\hline
\end{tabular}

$L_{\min \lambda}=$ Minimum Radinace of Band 6, QCal = Quantized Calibrated Pixel Value in DN $Q C a l_{\max }=$ Maximum quantized calibrated pixel value in $\mathrm{DN}$ and

$\mathrm{QCal}_{\min }=$ Minimum quantized calibrated pixel value in DN

Radiance,

$$
L_{\lambda}=M_{L} * Q C a l+A_{L}
$$

where,

$M_{L}=$ radiance multiplicative scaling factor

$A_{L}=$ Rdiance additive scaling factor for band (RADIANCE_MULT_BAND 10 and 11)

QCal = Pixel value in DN

Second, the thermal band calibration constants $\left(K_{1} \& K_{2}\right)$ are obtained from the metadata files of the corresponding years and the satellite temperature, $T$ (in degree Celsius) is calculated using Equation (3).

$$
T=\frac{K_{2}}{\ln \left(\frac{K_{1}}{L_{\lambda}}+1\right)}-273.15
$$

where, $K_{1} \& K_{2}=$ Thermal Band Calibration Constants

Lastly, the land surface temperature is estimated using Equation (4).

$$
L S T=\frac{T}{1+\left(\frac{\lambda T}{\rho}\right) * \ln (\varepsilon)}
$$

where,

$\lambda=$ Central band wavelength of emitted radiance

$T=$ Satellite temperature

$\varepsilon=$ Emmissivity (calculated using the Algorithm 5)

$$
\varepsilon=0.004 * P_{v}+0.986
$$

where, $P_{v}=$ Proportion of vegetation (calculated using the Algorithm 6)

$$
P_{v}=\left[\left(N D V I-N D V I_{\min }\right) /\left(N D V I_{\max }-N D V I_{\min }\right)\right]^{2}
$$

\subsection{Evaluating the Interactions of Land Use Change and Microclimate}

Regression analysis is widely used to present the relationships in various fields 
but this approach requires large number of temporal data. As this study is conducted based on the four time series data therefore, regression analysis is not feasible. In this study, the estimated temporal land use and surface temperature is compared graphically to explore their interactions. Lastly, vertical and horizontal transect profile is taken for better understanding of the local spatial variability of land use and land surface temperature.

\section{Results and Discussion}

\subsection{Land Use and River Morphology}

The land use land cover classification result depicts that, vegetation is the dominant land cover of the study area. The second dominant land cover is baresoil as the study area contains the Padma River with a long track of char land. The detail of the land use and land cover dynamics of the study area from 1989 to 2015 is shown in Figure 2.

From Table 3 it is apparent that almost $46 \%-59 \%$ of the land area is occupied by vegetation and a significant portion $24 \%-38 \%$ of the study area is baresoil. The proportion of builtup area is comparatively low than other land use land cover. In 1989 the aerial extent of the builtup area was only 2\% that has

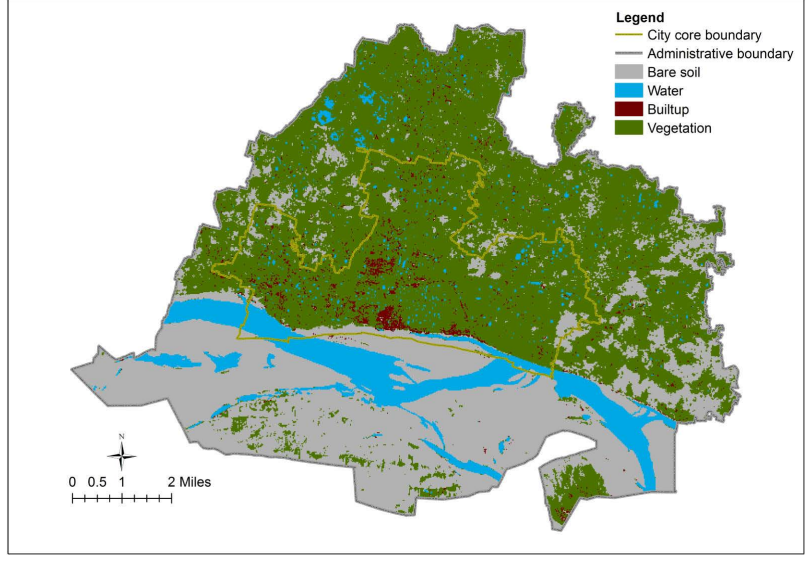

(a)

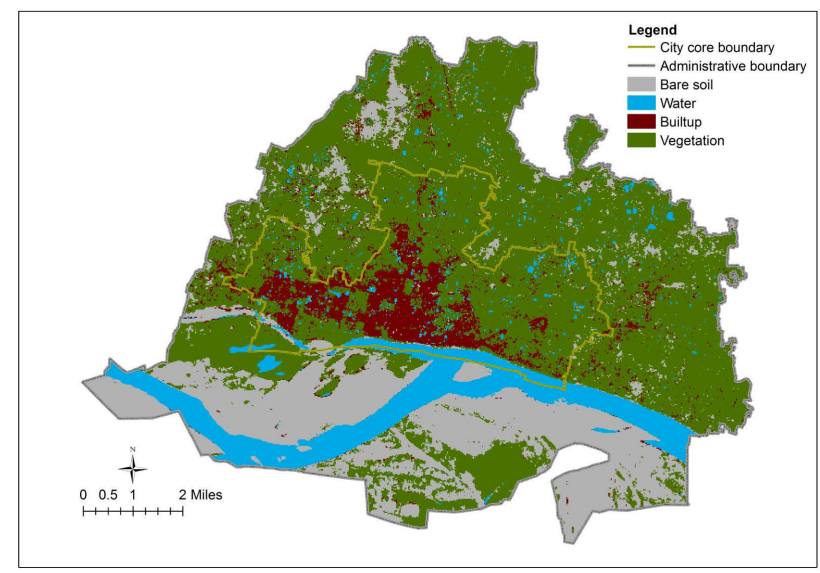

(c)

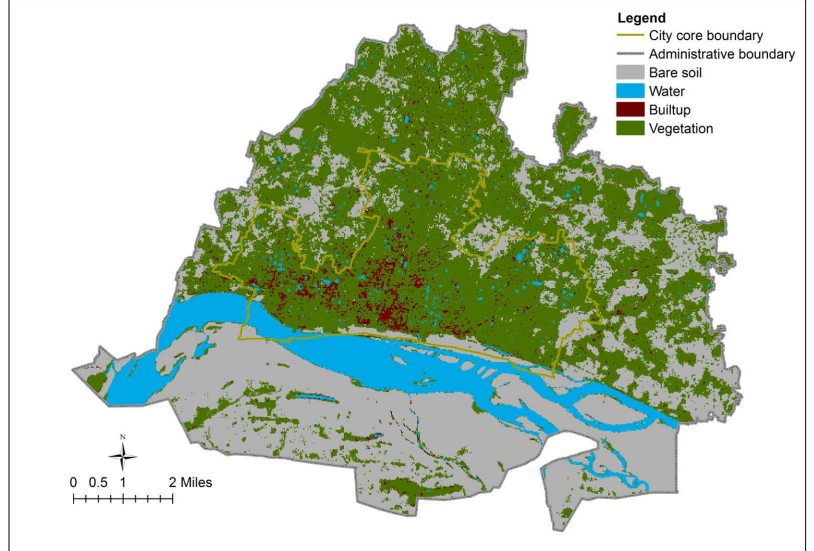

(b)

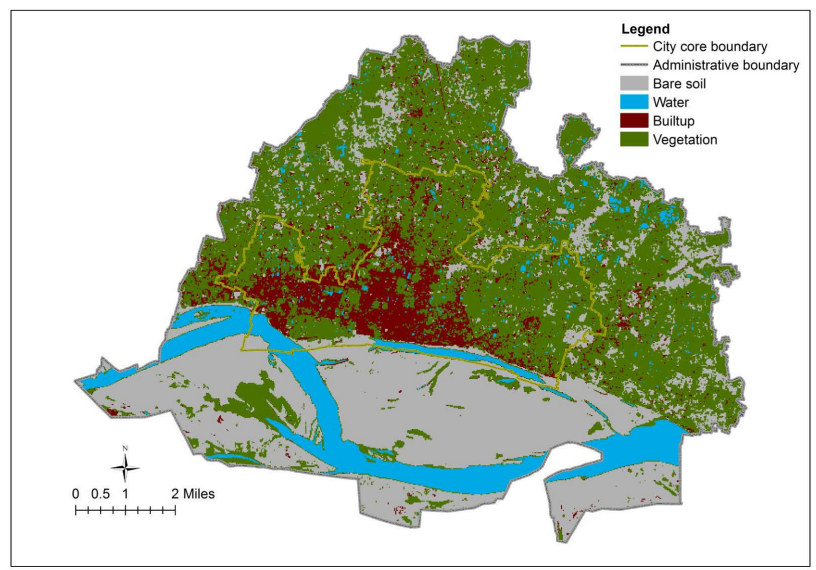

(d)

Figure 2. Land use land cover map of the study area (a) in 1989; (b) in 1996; (c) in 2005; (d) in 2015. 
Table 3. Proportion of land use land cover from 1989 to 2015.

\begin{tabular}{ccccc}
\hline Land use & 1989 & 1996 & 2005 & 2015 \\
\hline Water & 11 & 12 & 11 & 11 \\
Baresoil & 34 & 38 & 24 & 33 \\
Vegetation & 52 & 46 & 59 & 48 \\
Builtup & 2 & 4 & 7 & 9 \\
\hline
\end{tabular}

reached to $9 \%$ by 2015 . It is noteworthy that among all the land covers only builtup area shows an increasing trend. The relative change of land use land cover shows a decreasing trend in the vegetation and an increasing trend in the bare soil and builtup area (Figure 3). Over the last 10-year period from 2005 to 2015 the vegetative area is decreased about $10 \%$ and bare soil is increased about $10 \%$. The result demonstrate that the overall land use land cover and river morphology of the city is changing.

The adjacent river Padma played significant role to cool the city. However, the result demonstrate a significant change in the river Padma. In 1989 and 1996, the river was very close to the city core area (see Figure 2(a) and Figure 2(b)) but it shows a gradual shift in 2005 and 2015. In 2005, half of the river channel shifted away from the original location. The condition is further worsened in 2015 where the river is fully shifted except a small portion in the west part of the city (see Figure 2(d)). In terms of areal extent, a considerable change is also observed where the former width of the river channel was larger than current years. The result also demonstrate that as the river has shifted more heat generating bare soil is observed adjacent to the city core area.

\subsection{Land Surface Temperature (LST)}

The retrieved LST trend during 1989-2015 over Rajshahi Metropolitan area is shown in Figure 4. The result shows that both the maximum and minimum temperature is increased (Figure 5) and on average, the LST is increased by $2^{\circ} \mathrm{C}$ over the study area. To understand the variability of LST over different land covers 100 sample pixels for each land cover are taken and extracted the corresponding LST using ArcGIS 10.2 software. The results demonstrate LST vary over different land cover. As shown in Figure 6, it is evident that the mean temperature is highest for the bare soil that is followed by built up area, vegetation and water.

\subsection{Meteorological Condition}

To measure the quantitative information of the effects of land use land cover change on the microclimate the meteorological data during 1980-2015 is assessed. The statistical result shows that the annual average precipitation and wind speed is declined (Figure 7 \& Figure 8). On the other hand, average annual relative humidity is increased (Figure 9) and annual maximum temperature prevails to be similar (Figure 10). In summary, it can be concluded that the global climatic condition of the city is also changing. 


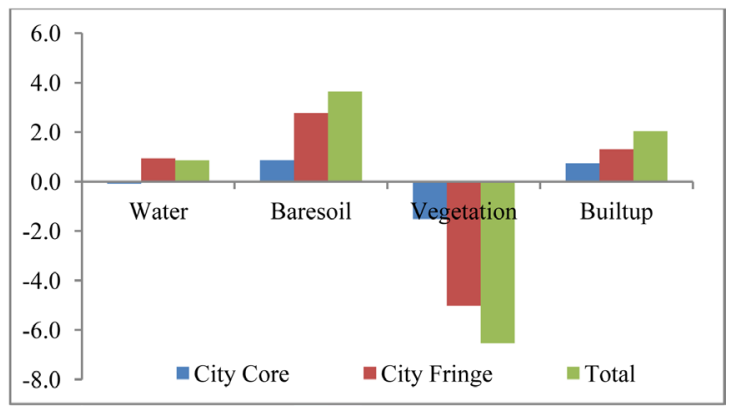

(a)

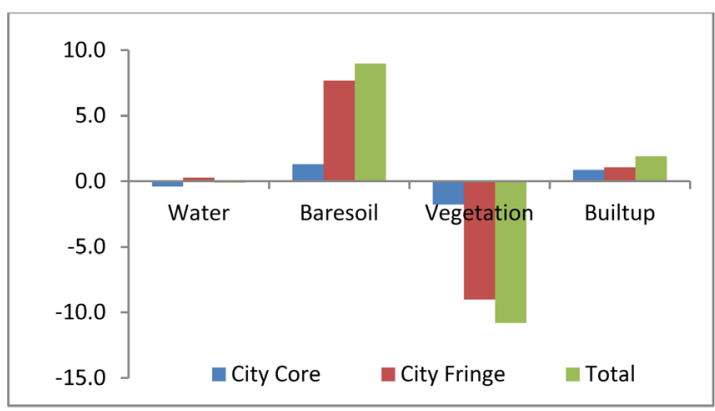

(b)

Figure 3. Relative land use land cover change (in percentage) (a) 1989 to 1996; (b) 2005 to 2015.

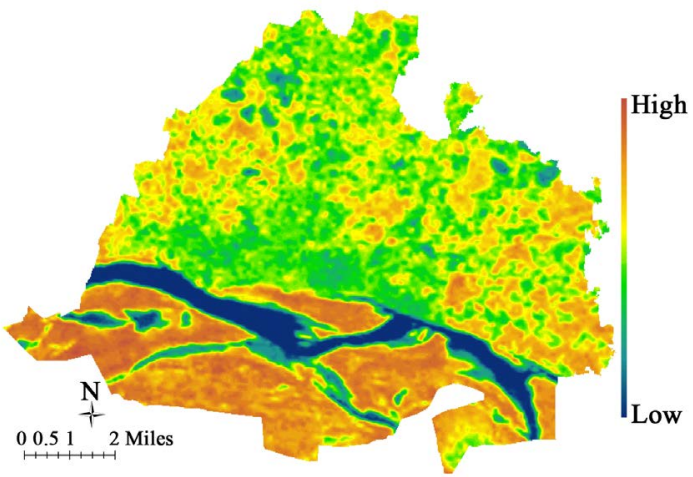

(a)

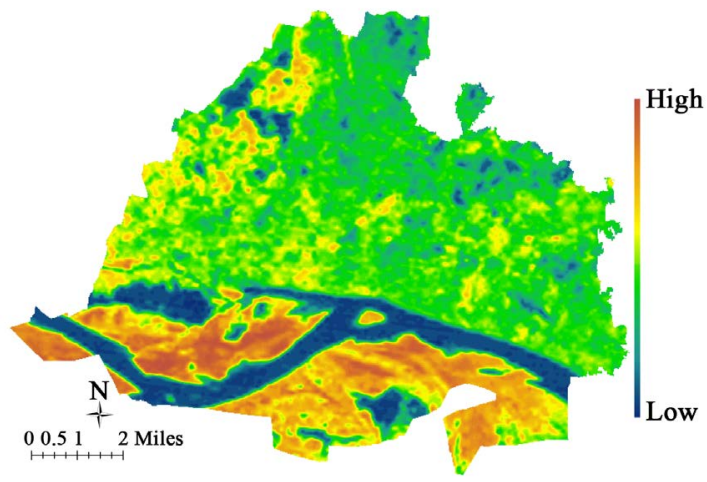

(c)

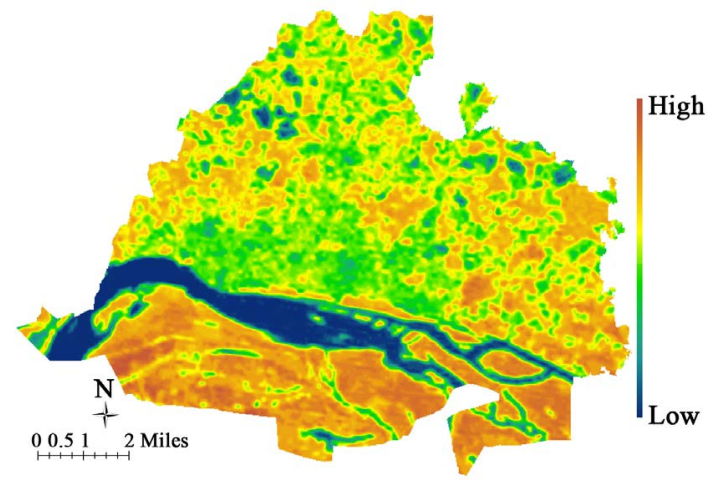

(b)

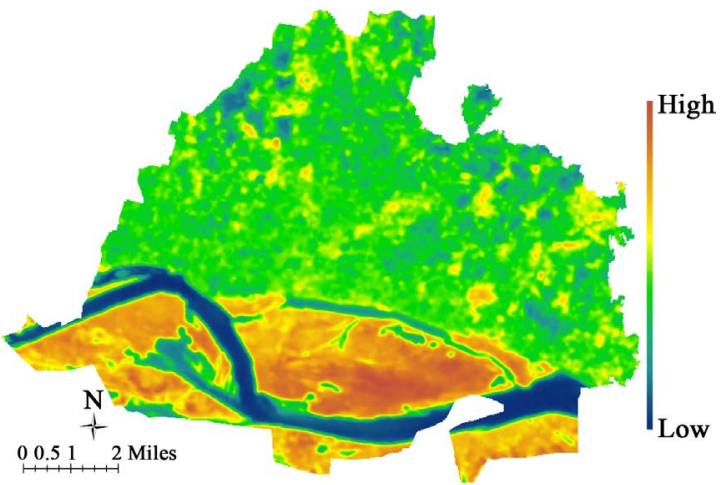

(d)

Figure 4. Land surface temperature in ${ }^{\circ} \mathrm{C}$ (a) in 1989; (b) in 1996; (c) in 2005; (d) in 2015.

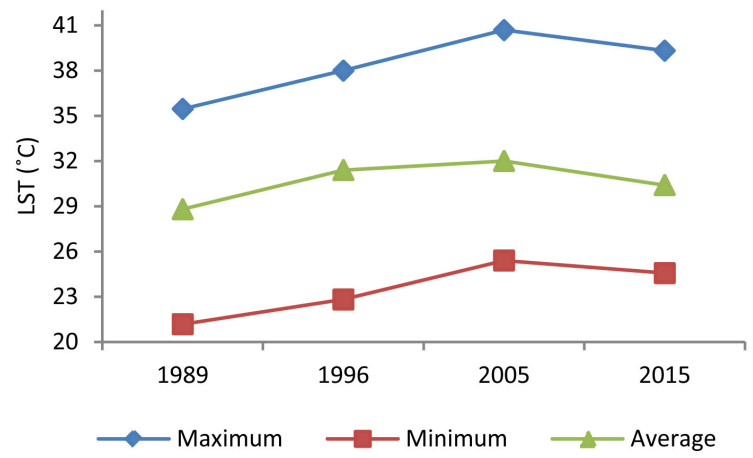

Figure 5. Trend of LST in ${ }^{\circ} \mathrm{C}$. 


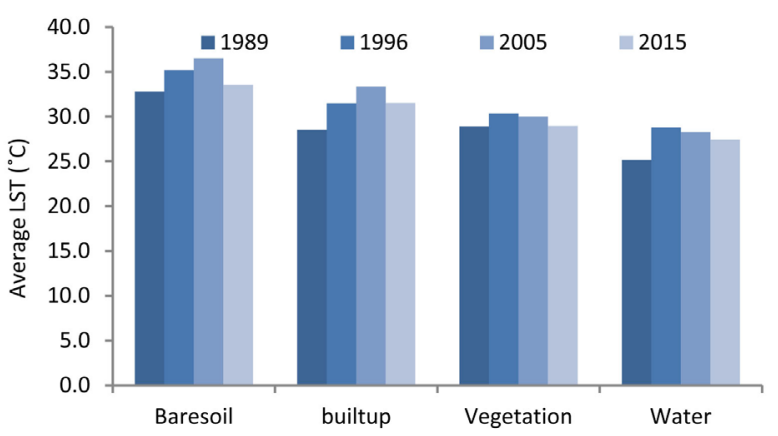

Figure 6. Mean LST by land use land cover.

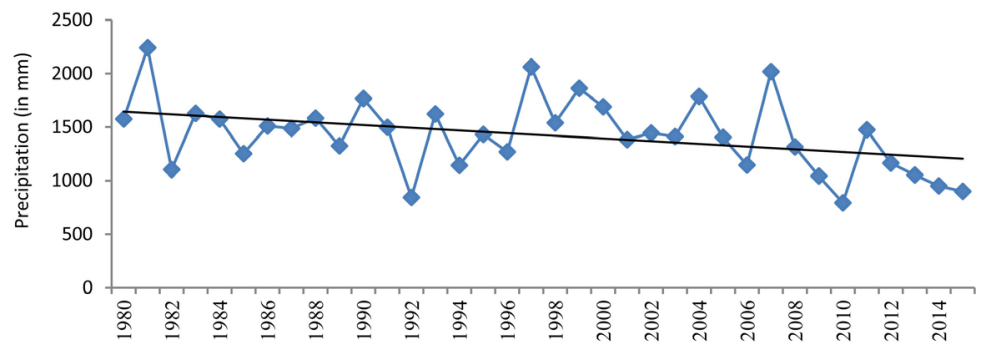

Figure 7. Average annual precipitation trend.

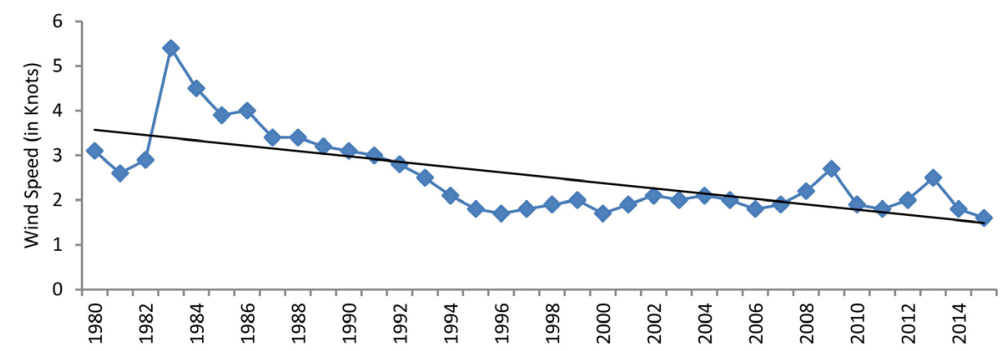

Figure 8. Average annual wind speed.

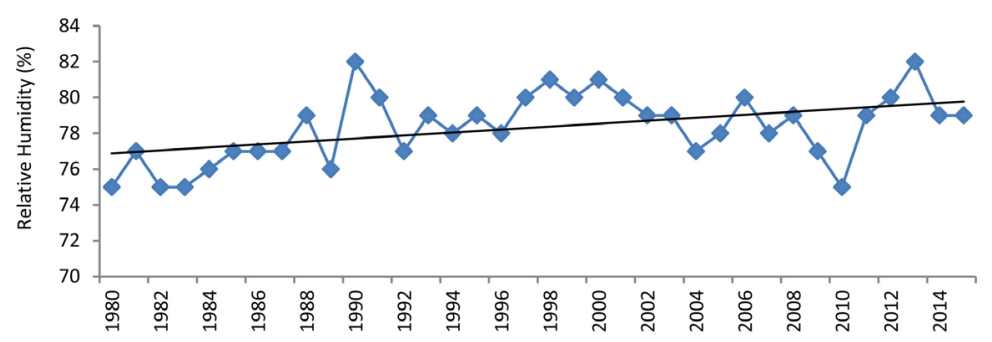

Figure 9. Average annual relative humidity.

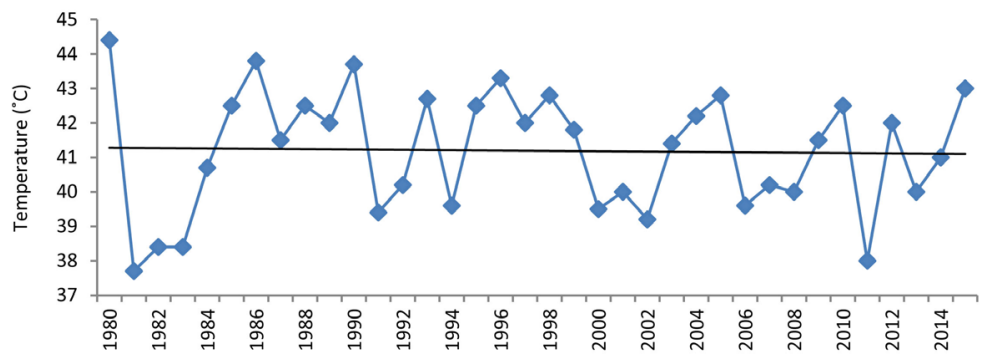

Figure 10. Annual maximum temperature trend. 


\subsection{Assessment of the Microclimate}

The result of historical growth of the study area presents two-way linear expansion along North-South and East-West direction. Moreover, all the built up areas are concentrated in the city centre thus two transect profiles (Vertical: North to South and Horizontal: East to West) are taken to describe the relative change in the LST and land use during 1989 to 2015. The vertical profile of the city (Figure 11) shows that the river area generates least LST and char lands adjacent to the river generates highest LST for all the years. As the builtup area was very limited during 1989 to 1996 therefore, no significant difference in the LST is observed in the city centre and city fringe during this period (Figure 11(a) and Figure 11(b)). With increasing trend in the builtup areas the city centre shows an increasing trend in the LST in 2005 and 2015 (Figure 11(c) and Figure 11(d)). More importantly, it is noticed that as the river shifted away from the city the bare soil is generating more LST and resulting to warm the air temperature. In contrary, the horizontal transect profile demonstrate that in 1989 the city fringe experienced more LST than city core area. The similar trend is observed in 1996 because the city fringe contained more bare soil thus the concentration of LST was highest in the city fringe than the city core during 1989 to 1996 (Figure 12(a) and Figure 12(b)). As shown in Figure 12(c) and Figure 12(d), it is evident that the city fringe gradually experiences less LST and the core area experiences more LST. The result suggest that the proportion of builtup area is increased in the city core and bare soil decreased in the eastern part of the study area.

The relationship between the dynamics of land use land cover and LST is further assessed by taking 100 sample pixels on each classified images and the corresponding LST is extracted for each land cover. The result shows that there is significant variation in the LST with change in the land cover pattern. Figure 13(a) and Figure 13(b) shows that, with increasing trend in the built up areas the corresponding LST is also increasing. Figure 14(a) and Figure 14(b) shows the relationship between vegetation and LST and it is apparent that vegetation is the dominant land cover and no significant variation is observed during 1989-2015. The relationship between water and LST shows a slight change in the distribution of LST as the water area is changed slightly (Figure 15(a) and Figure 15(b)). Lastly, the second dominant land cover bare soil shows the highest concentration of LST in all the years with a little temporal variation (Figure 16(a) and Figure 16(b)).

The results demonstrate that the study area did not experience too much land use and land cover change except the city centre. Particularly, more change is observed in the Padma river channel. As water, area is decreasing and shifting away from the original location so the cooling effect is decreasing. Consequently, the resulted bare soil has increased adjacent surface temperature of the city. In summary, it is apparent that change in land use land cover specially the bare soil and built up area influence the local surface temperature that helps to alter the microclimate of the city. 


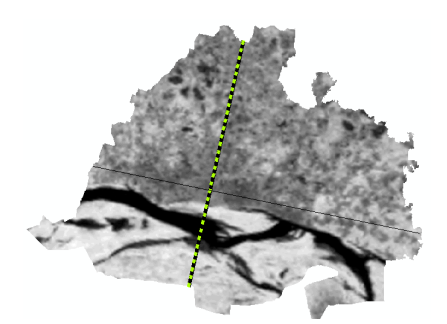

Vertical profile of the city (North-South)

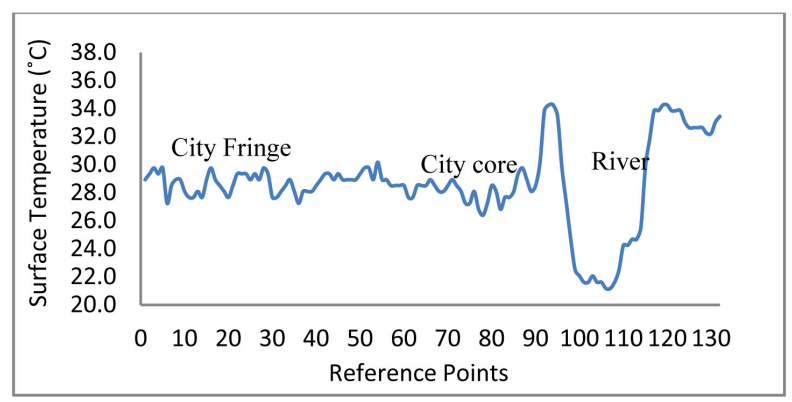

(a)

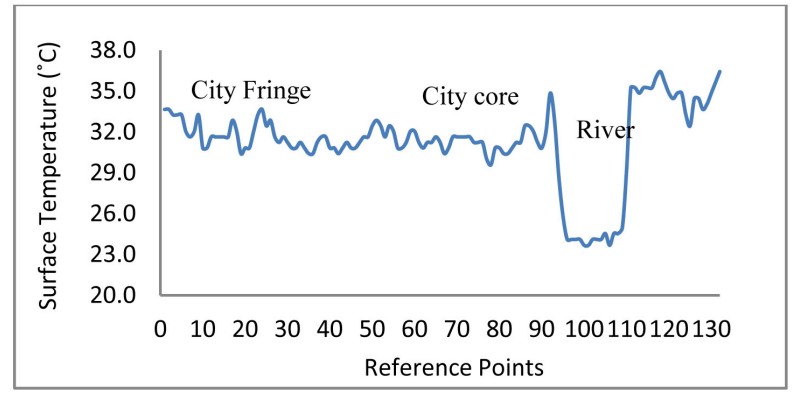

(b)

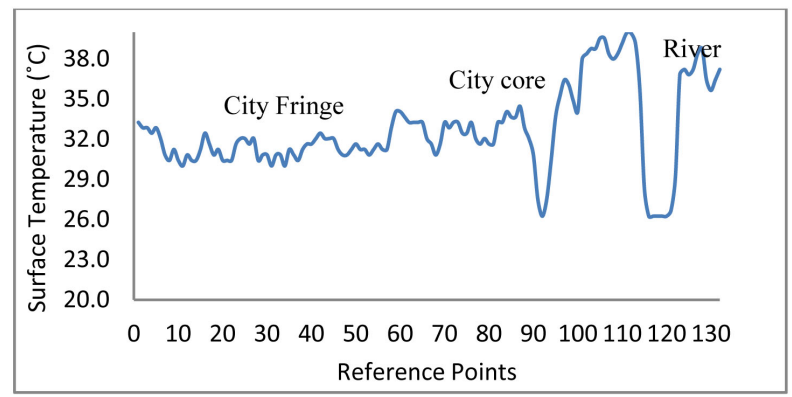

(c)

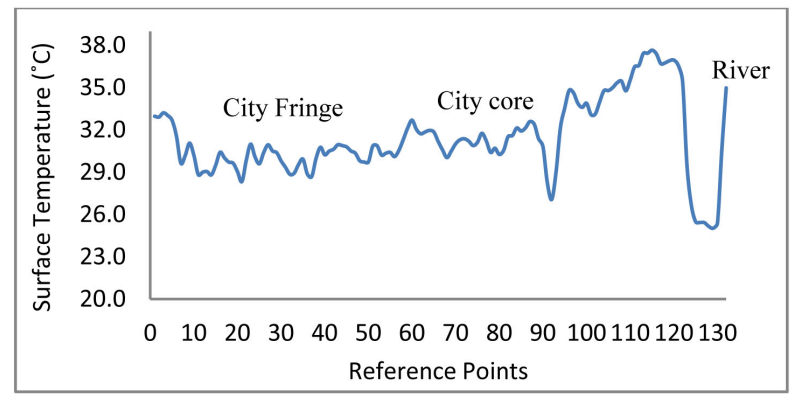

(d)

Figure 11. Vertical profile of the city by LST (North-South). 


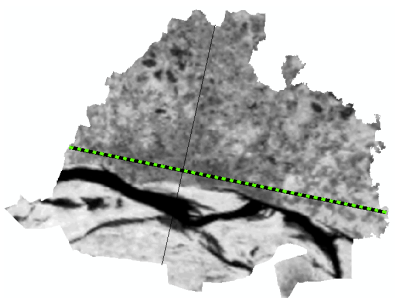

Horizontal profile of the city (West-East)

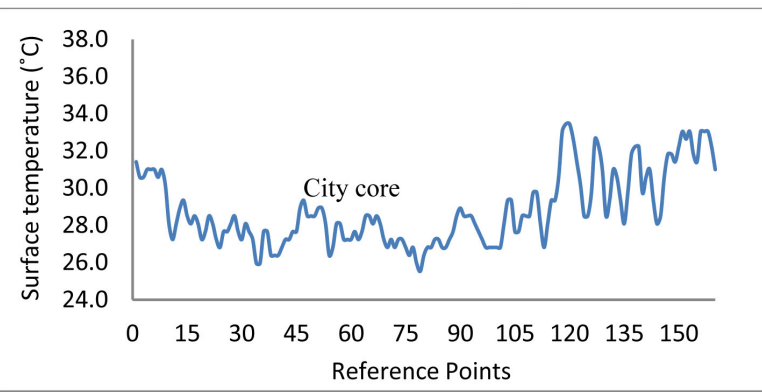

(a)

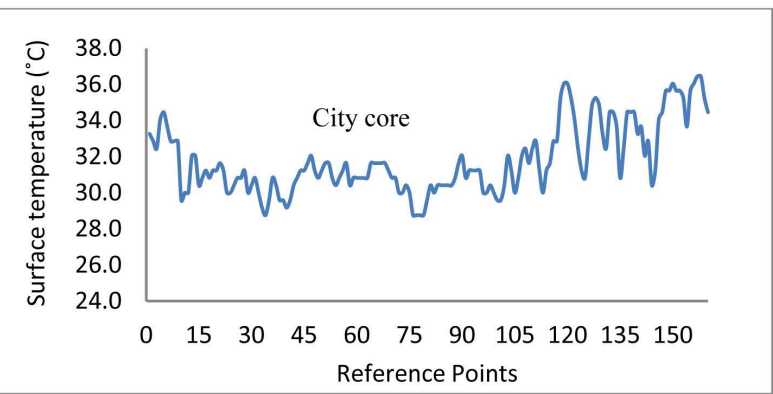

(b)

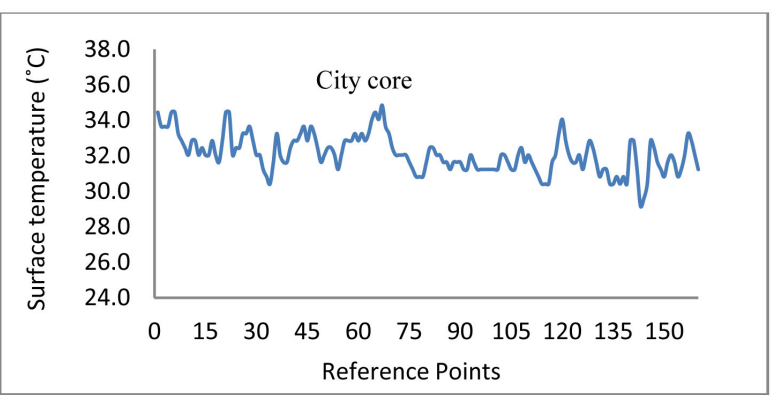

(c)

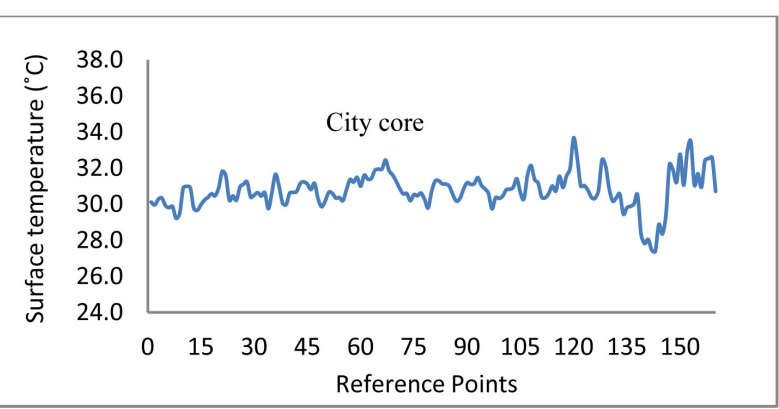

(d)

Figure 12. Horizontal profile of the city by LST (West-East). 


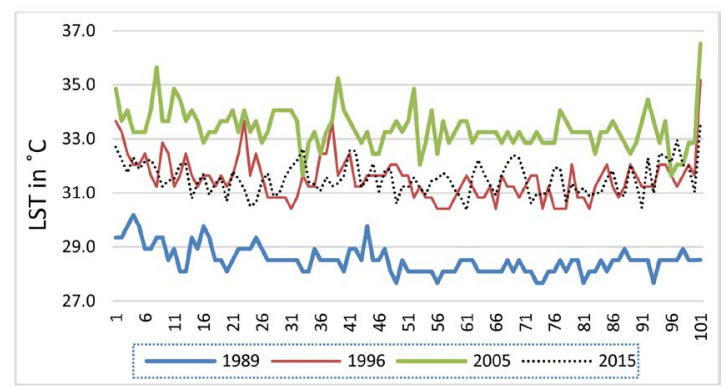

(a)

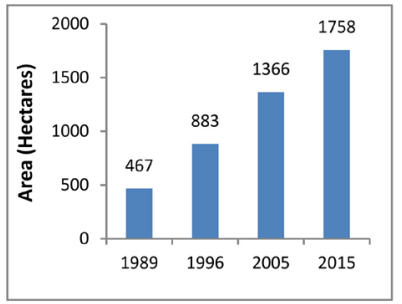

(b)

Figure 13. (a) Correlation between builtup area and LST $\left({ }^{\circ} \mathrm{C}\right)$; (b) trend of builtup area.

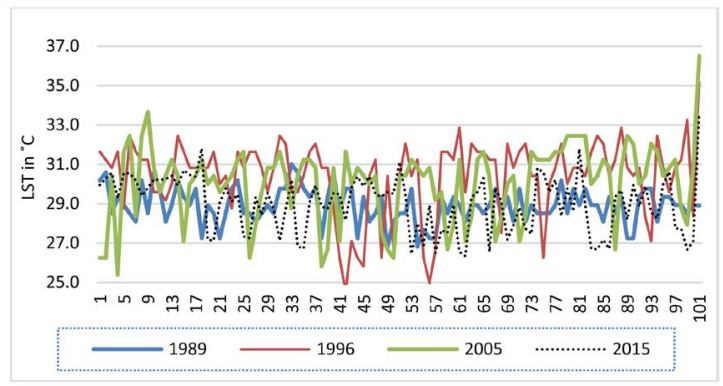

(a)

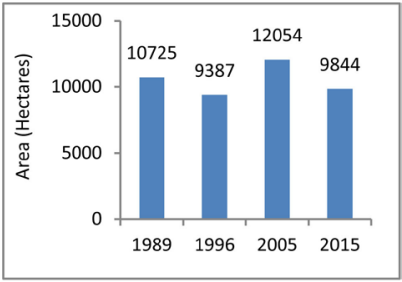

(b)

Figure 14. (a) Correlation between vegetative area and LST $\left({ }^{\circ} \mathrm{C}\right)$; (b) trend of vegetation.

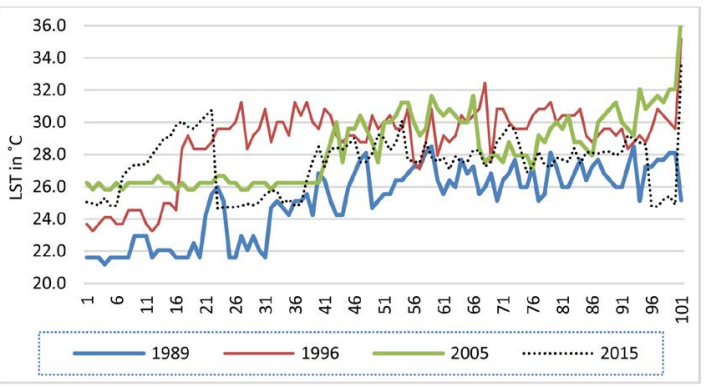

(a)

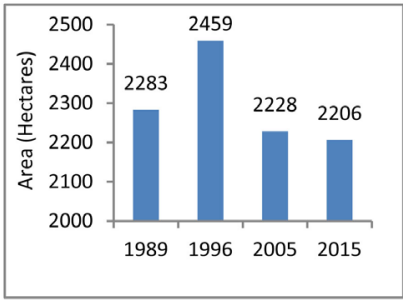

(b)

Figure 15. (a) Correlation between water area and LST $\left({ }^{\circ} \mathrm{C}\right)$; (b) trend of water.

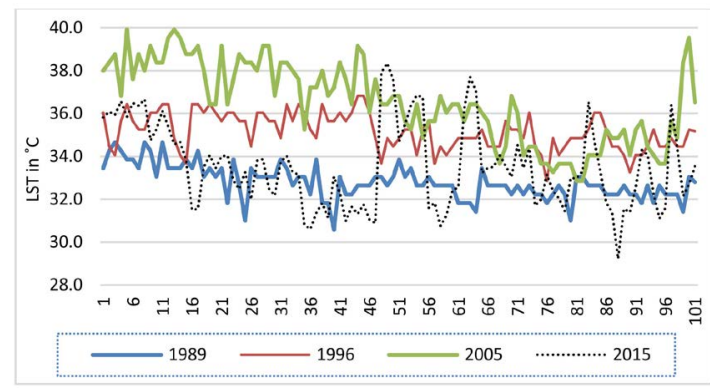

(a)

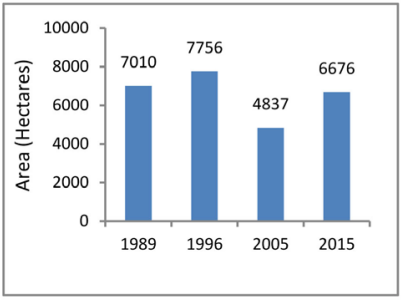

(b)

Figure 16. (a) Correlation between baresoil and LST ( $\left.{ }^{\circ} \mathrm{C}\right)$; (b) trend of baresoil.

\section{Conclusion}

In this study, time series data Landsat- $5 \mathrm{TM}$ and Landsat- 8 OLI are used to ob- 
tain land use land cover information and surface temperature for the period of 1989 to 2015 . During the study period, the city core area experienced significant changes in the land cover than its surroundings. In addition, the river Padma has also experienced huge morphological change. Among all the four types of land cover, the builtup areas show an increasing trend both in the city core and city fringe. The changing pattern of land use and land cover influences urban microclimate at several scales [5] and LST is a key factor that results the interaction between land surface and atmosphere [6] thus LST is used to assess the relations with the land use and land cover. The spatial statistics of the land surface temperature demonstrate an increasing trend for the period of 1989 to 2015 . The bare soil generates highest surface temperature that is followed by builtup area. The transect profile of the study area represents a significant variation in LST. In addition, the meteorological data analysis illustrates that the city has experienced adverse climatic condition with increase in the relative humidity, temperature and decrease in the average annual rainfall land wind speed. The results point to the fact that land use land cover change affects the microclimate of the city. As urbanization expands throughout the world, it is expected that rapid and unplanned urbanization might affect surface temperature in other countries and regions [10]. Therefore, detail climatic factors should be considered when evaluating land use and land cover change impact on the microclimate. In this study, the spatial variability between land use and surface temperature are used as the influencing factors of microclimate. In contrary, a generalized correlation is performed between surface temperature and other climatic factors. As the study area contains only one meteorological station therefore, local spatial variability of the climatic factors are not correlated to surface temperature at local level. Though, land use is considered as the potential factors of urban microclimate, other climatic factors for example topographic, air temperature, water information, relative humidity and soil information should be integrated to obtain local spatial variability of the microclimate in near future.

\section{Acknowledgements}

United States Geological Survey (USGS) for providing Landsat imagery.

Bangladesh Metrological Department (BMD) for providing meteorological data.

Rajshahi Development Authority (RDA) for proving administrative boundary of the study area.

\section{References}

[1] Hathway, E.A. and Sharples, S. (2012) The Interaction of Rivers and Urban Form in Mitigating the Urban Heat Island Effect: A UK Case Study. Building and Environment, 58, 14-22. http://dx.doi.org/10.1016/j.buildenv.2012.06.013

[2] Zhao, M., Cai, H., Qiao, Z. and Xu, X. (2016) Influence of Urban Expansion on the Urban Heat Island Effect in Shanghai. International Journal of Geographical Information Science, 30, 1-21.

[3] Huang, L., Li, J., Zhao, D. and Zhu, J. (2008) A Fieldwork Study on the Diurnal 
Changes of Urban Microclimate in Four Types of Ground Cover and Urban Heat Island of Nanjing, China. Building and Environment, 43, 7-17. https://doi.org/10.1016/j.buildenv.2006.11.025

[4] Obiakor, M., Ezeonyejiaku, C. and Mogbo, T. (2012) Effects of Vegetated and Synthetic (Impervious) Surfaces on the Microclimate of Urban Area. Journal of Applied Sciences \& Environmental Management, 16, 85.

[5] Stabler, L.B., Martin, C.A. and Brazel, A.J. (2005) Microclimates in a Desert City Were Related to Land Use and Vegetation Index. Urban Forestry \& Urban Greening, 3, 137-147. https://doi.org/10.1016/j.ufug.2004.11.001

[6] Jalan, S. and Sharma, K. (2014) Spatio-Temporal Assessment of Land Use/Land Cover Dynamics and Urban Heat Island of Jaipur City Using Satellite Data. International Archives of the Photogrammetry, Remote Sensing and Spatial Information Sciences, XL-8, 767-772. https://doi.org/10.5194/isprsarchives-XL-8-767-2014

[7] Kottmeier, C., Biegert, C. and Corsmeier, U. (2007) Effects of Urban Land Use on Surface Temperature in Berlin: Case Study. Journal of Urban Planning and Development, 133, 128. https://doi.org/10.1061/(ASCE)0733-9488(2007)133:2(128)

[8] Fu, P. and Weng, Q. (2016) A Time Series Analysis of Urbanization Induced Land Use and Land Cover Change and Its Impact on Land Surface Temperature with Landsat Imagery. Remote Sensing of Environment, 175, 205-214.

https://doi.org/10.1016/j.rse.2015.12.040

[9] Buyadi, S.N.A., Mohd, W.M.N.W. and Misni, A. (2015) Vegetation's Role on Modifying Microclimate of Urban Resident. Procedia-Social and Behavioral Sciences, 202, 400-407. https://doi.org/10.1016/j.sbspro.2015.08.244

[10] Zhu, X., Chen, G., Sha, W., Iwasaki, T., Li, W. and Wen, Z. (2014) The Role of Rapid Urbanization in Surface Warming over Eastern China. International Journal of Remote Sensing, 35, 8295-8308. https://doi.org/10.1080/01431161.2014.985397

[11] Pathirana, A., Denekew, H.B., Veerbeek, W., Zevenbergen, C. and Banda, A.T. (2014) Impact of Urban Growth-Driven Land Use Change on Microclimate and Extreme Precipitation-A Sensitivity Study. Atmospheric Research, 138, 59-72. https://doi.org/10.1016/j.atmosres.2013.10.005

[12] Meng, F. and Liu, M. (2013) Remote-Sensing Image-Based Analysis of the Patterns of Urban Heat Islands in Rapidly Urbanizing Jinan, China. International Journal of Remote Sensing, 34, 8838-8853. https://doi.org/10.1080/01431161.2013.853895

[13] Raja, D.R. (2012) Spatial Analysis of Land Surface Temperature in Dhaka Metropolitan Area. Journal of Bangladesh Institute of Planners, 5, 151-167. https://pdfs.semanticscholar.org/3977/6c5e7dc1960dc18b0d8cebd88639b6e50935.pdf

[14] Bayes, A., Md, K., Xuan, Z., Shahinoor, R.M. and Keechoo, C. (2013) Simulating Land Cover Changes and Their Impacts on Land Surface Temperature in Dhaka, Bangladesh. Remote Sensing, 5, 5969-5998. https://doi.org/10.3390/rs5115969

[15] Hasan, K.F., Morshed, M.M. and Ali, M.S. (2014) A Satellite Based Method to Determine Land Surface Temperature from NOAA-AVHRR Digital Data. Journal of the Bangladesh Electronic Society, 87-92.

[16] DDC Structure Plan (2003) Master Plan and Detailed Area Development Plan for Rajshahi Metropolitan City. Working Paper on Urbanization and Demography. Development Design Consultants Limited, West Bergholt.

[17] Lima, F.K. (2003) Problems and Constraints in Implementing Master Plans: A Case Study of Rajshahi City. Department of Urban and Regional Planning, Bangladesh University of Engineering and Technology, Dhaka. 
Submit or recommend next manuscript to SCIRP and we will provide best service for you:

Accepting pre-submission inquiries through Email, Facebook, LinkedIn, Twitter, etc. A wide selection of journals (inclusive of 9 subjects, more than 200 journals)

Providing 24-hour high-quality service

User-friendly online submission system

Fair and swift peer-review system

Efficient typesetting and proofreading procedure

Display of the result of downloads and visits, as well as the number of cited articles Maximum dissemination of your research work

Submit your manuscript at: http://papersubmission.scirp.org/

Or contact jgis@scirp.org 